\title{
MODERNIDAD LITERARIA Y DISCURSO ENSAYÍSTICO EN LOS RETRATOS REALES E IMAGINARIOS, DE Alfonso ReyeS
}

Víctor Barrera Enderle

(Universidad Autónoma de Nuevo León, Monterrey, México)

\section{Alfonso Reyes y el ensayo hispanoamericano}

Durante mucho tiempo, la obra, miscelánea e «inestable», que Alfonso Reyes (1889-1959) escribió y publicó en los primeros años de su estancia madrileña, fue vista como secundaria, como «prosa para pagar las cuentas» y sobrevivir con una familia a cuestas en ese «autoexilio», que el joven autor regiomontano se impuso tras la muerte violenta de su padre, el general Bernardo Reyes, en la tristemente célebre Decena Trágica': el levantamiento armado contra el presidente Madero en febrero de 1913, que terminó con su asesinato y la ascensión al poder de Victoriano Huerta. Notas, traducciones, ensayos, estudios filológicos, todo un repertorio escritural que Reyes fue ordenando y dándole un sentido a través de diversas publicaciones (que él mismo se encargaba de recopilar y reagrupar en libros). Ahora podemos ver en esa producción un ejercicio, crítico y creativo, que buscaba desestabilizar la rigidez del canon literario del orbe hispánico e introducir nuevas modalidades narrativas que se apartaban de la autoridad de la filología y de la perspectiva lineal y racional de la historia literaria.

El periodo de gestación y ejecución de este ejercicio literario cubre algo más que un lustro y algo menos que una década; parte de la llegada de Reyes a Madrid en 1914 y culmina con la redacción de Ifigenia cruel en 1923. Entre estos años, la literatura mexicana en particular y la hispanoamericana en general experimentan una serie de transformaciones profundas que, a grandes rasgos, podríamos definir como la transición del modernismo a las vanguardias, pero, con ello, nos

\footnotetext{
1 En la «Oración del 9 de febrero», escrita en Buenos Aires en 1930, Reyes evoca así la pérdida: «Hace 17 años murió mi pobre padre [...]. De repente sobrevino la tremenda sacudida nerviosa, tanto mayor cuanto que la muerte de mi padre fue un accidente, un choque contra un obstáculo físico, una violenta intromisión de la metralla en la vida y no el término previsible y paulatinamente aceptado de un acabamiento biológico» [Reyes, 1990: 25-27].
} 
faltaría algo más: la intensa metamorfosis padecida por la producción ensayística latinoamericana, y de la cual Reyes fue uno de sus más grandes artífices. El ensayo hispanoamericano, o tal vez sería mejor Ilamarlo el discurso ensayístico, pues más que un género literario específico ha sido una estrategia (y un dispositivo) de lectura y apropiación de diversas tradiciones tanto literarias como culturales, ha sido un especio de exploración formal y temática de la identidad y de las diversas maneras de expresión desarrolladas en la región².

Si bien, durante buena parte del siglo XIX, el discurso ensayístico hispanoamericano se centró en el problema fundamental de la identidad política y nacional (partiendo de la «Carta de Jamaica» de Simón Bolívar en 1815 hasta llegar a «Nuestra América» de José Martí en 1891), comenzó a experimentar profundos cambios con la publicación, al despuntar el siglo XX, de Ariel, de José Enrique Rodó. Podríamos decir, de manera general, que de la obsesión por la diferencia (por encontrar el rasgo particular) dio paso a la indagación de la relación con la cultura occidental en pleno auge de la modernidad.

Las trasformaciones políticas y económicas, experimentadas en la mayoría de los países hispanoamericanos durante el cambio de siglo, representaron una readecuación profunda de los campos literarios. El modernismo significó, entre otras cosas, el replanteamiento de la función del escritor y de la literatura dentro de las sociedades. El reordenamiento de las actividades estéticas en los incipientes modelos capitalistas de producción, en pocas palabras, las demandas de un sector minoritario, el de los escritores, que exigía, a su manera, nuevas formas de representación.

El ensayo de Rodó alertaba a la juventud privilegiada de América Latina sobre la necesidad de retomar (o tomar por vez primera) las riendas de los controles políticos y pedagógicos: reinstalar el modelo humanista en la enseñanza y combatir los excesos del positivismo, la industrialización y la, por él Ilamada, «nordomanía» (esto es, el amor excesivo a la cultura estadounidense). ¿Dónde ubicar, en el interior de la novísima estratificación moderna de la sociedad hispanoamericana, al escritor, al artista y, en última instancia, al discurso ensayístico? «Afirmado primero en el baluarte de vuestra vida interior, Ariel se lanzará desde allí a la conquista de las almas», les advertía el viejo «Próspero» (el narrador del Ariel) a su joven auditorio: «Yo lo veo, en el porvenir, sonriéndoos con gratitud, desde lo alto, al sumergirse en la sombra de vuestro espíritu» [Rodó, 1957: 243].

\footnotetext{
2 El académico argentino Claudio Maíz expone al respecto: «El discurso ensayístico, por tratarse de una producción discursiva netamente de la modernidad, nos obliga a formular algunos interrogantes en torno a la estrecha vinculación existente entre el marco histórico-cultural y la emergencia de la prosa ensayística. La emergencia del ensayo es un fenómeno literario en el que están en juego de manera decisiva diversos factores cosmovisionarios de la época moderna» [2004: 40-41]. Para ampliar sobre el tema, véanse mis ensayos El centauro ante el espejo. (Charlas y apuntes sobre el ensayo) [2017] y Lectores insurgentes. La formación del discurso crítico hispanoamericano (1810-1870) [2013].
} 
Estos jóvenes, disgregados por todo el continente, tomaron pronto la batuta, asumieron el espíritu arielista y comenzaron a abogar por la profesionalización de las otrora llamadas carreras liberales. Reyes, temprano lector de Rodó, dijo, al morir este en 1917, en uno de los ensayos que integran El cazador: «Y entonces la primera lectura de Rodó nos hizo comprender a algunos que hay una misión solidaria en los pueblos, y que nosotros dependíamos de todos los que dependían de nosotros. A él, en un despertar de la conciencia, debemos algunos la noción exacta de la fraternidad americana» [Reyes, 1980: 134].

La estrategia para alcanzar esa profesionalización no solo consistía en un ejercicio crítico de lectura, sino en la experimentación con diversos géneros prosísticos, principalmente el ensayo. Reescribir la tradición y, al hacerlo, apropiarla. Establecer vínculos entre diversas corrientes y movimientos literarios y estéticos. Todo ello a través de la readecuación, como sugiere Robert T. Conn en su ensayo The Politics of Philology. Alfonso Reyes and the Invention of the Latin American Literary Tradition, de los usos de la filología para tratar de establecer un «estado estético» en contrapeso con el estado político: «The Fundation upon which Reyes built his Asthetic State, I argue, was philology. In this book, I deal with several philological traditions. The first is the concept of literary tradition itself, based upon the figures of Lessing, Winckelmann, Humboldt, Schiller and Goethe» [Conn, 2002: 16]. Las otras tradiciones filológicas, señaladas por Conn, serían la filología clasicista de Weimar, la filología española y la filología comparatista (organizada por Schlegel, Bopp y los hermanos Grimm)³.

Yo agregaría, a la apropiación de la filología, el desarrollo del discurso ensayístico. Si con el manejo de los diversos tipos filológicos la generación de Reyes podría reinterpretar la tradición y el canon literarios, con el ensayo podría modificarlos paulatinamente. Hay un factor importante: la condición subordinada que, simbólicamente, se les otorgaba a las literaturas hispanoamericanas, y que se remontaba a los días de la emancipación política. La independencia debería completarse con la autonomía cultural. El ensayo se convertía así no solo en una expresión literaria, sino en un dispositivo político y pedagógico. Este aspecto será fundamental a la hora de revisar la producción ensayística alfonsina de estos años formativos.

\footnotetext{
${ }^{3}$ Ya Foucault, en Las palabras y las cosas, había apuntado la importancia de la filología como un modo discursivo hegemónico de la modernidad: «Con la literatura, con el retorno de la exégesis y la preocupación por la formalización, con la constitución de una filología, en breve, con la reaparición del lenguaje en un aumento múltiple, puede borrarse de ahora en adelante el orden del pensamiento clásico [...]. Separado de la representación, el lenguaje no existe de ahora en adelante y hasta llegar a nosotros más que de modo disperso: para los filólogos las palabras son como otros tantos objetos constituidos y depositados por la historia» [1978: 295-297]. Por su parte, Edward Said sostenía: «La labor del filólogo debe ser la de vincular con el presente ese momento inmediatamente posterior a la caída, posterior a su vez al nacimiento del lenguaje, para después mostrar cómo la densa red de relaciones existentes entre los usuarios del lenguaje es una red secular de la que emergerá el futuro» [2004: 370].
} 
La nueva generación de ensayistas, con Reyes a la cabeza, se enfrentó al desafío de reordenar las políticas culturales y educativas de sus respectivos países, pero al mismo tiempo se instaló en la prensa y trató de reconfigurar la opinión pública y los campos literarios. El proceso, sin embargo, no fue continuo. Previamente, mucho de ellos tuvieron que experimentar la censura y el exilio, la persecución y la imposición del olvido.

Tal era el panorama cuando Alfonso Reyes cruzó los Pirineos (escapando de Francia en pleno inicio de la primera guerra mundial). Al llegar a Madrid no tendría otro medio de subsistencia que la escritura. "Yo he venido, como Ruiz de Alarcón, a pretender en corte, a ver si me gano la vida» [Reyes, 2010: 13], consignó en su Diario el 2 de octubre de 1914. Su primer trabajo, para «salir del atolladero», fue la traducción de la Historia de la guerra europea, que había comenzado a publicar en Francia Gabriel Hanotaux. Al poco tiempo empieza a involucrarse en el ambiente literario y cultural de la capital española. En Las vísperas de España, un libro editado en Buenos Aires en 1937 (en pleno desarrollo de la Guerra Civil), recordaría con nostalgia:

\footnotetext{
A raíz de mi llegada a Madrid [...], me relacioné con la gente del Ateneo (Secretario, Manuel Azaña), que más tarde me honraría nombrándome Secretario de su Sección Literaria; me relacioné con el Centro de Estudios Históricos, donde me cupo la suerte de trabajar durante cinco años bajo la dirección de D. Ramón Menéndez Pidal, y rodeado de la compañía y consejo de Américo Castro, Federico de Onís, Tomás Navarro Tomás, Antonio G. Solalinde, Justo Gómez Ocerín. Mi fraternal amigo Enrique Díez-Canedo me puso en contacto con los señores Velasco y Acebal, que me acogieron tan gentilmente en la colección clásica de «La Lectura» [1995: 40-41].
}

\section{La gestación de los retratos}

El primer golpe de timón lo dio Alfonso Reyes con Visión de Anáhuac ${ }^{4}$ (publicado en Costa Rica en 1917): estrategia narrativa para dotar de peso simbólico a su escritura e instalarla en una tradición particular. Como escritor proveniente de uno de los márgenes debía trabajar con ciertos registros y confeccionar géneros discursivos alternativos que le permitieran no solo el ingreso al campo cultural sino la subversión del canon literario hispánico. El ensayo se convertiría en el género idóneo para este fin, pues representaba una manera heterogénea de relacionarse con ciertas tradiciones y la mejor vía para construir otras formas de genealogía literaria. Su estilo fue transformándose

\footnotetext{
${ }^{4}$ Sobre el particular, véase mi ensayo «El reverso del tapiz: la escritura de Visión de Anáhuac» [2016: 145-156].
} 
paulatinamente, muchos de sus textos «se escribieron sobre las rodillas, en las posadas y en la calle. Al tono desbordado de las Cuestiones estéticas [su primer libro de ensayos, publicado en 1911 en París] sucede un estilo incisivo y corto. Me enfrento con un mundo nuevo y procedo conforme a la estética de la "instantánea" y cediendo al primer sabor de la sorpresa» [1990: 173].

La escritura de Visión de Anáhuac se compaginó con la integración de su autor al circuito letrado de Madrid, a través del trabajo en la prensa y el ya referido Centro de Estudios Históricos. Desde esos espacios fue introduciendo formas narrativas en apariencia simples, pero que respondían a complejos procesos de invención y articulación crítica. Las fuentes de estos trabajos heterogéneos se encontraban en diversos universos letrados: ensayistas y tratadistas ingleses, biógrafos franceses e incluso escritores latinoamericanos poco conocidos en el ambiente cultural peninsular (como fray Servando Teresa de Mier). En particular, me interesa resaltar aquí el cultivo de un género literario poco abordado por los estudios especializados: la vida imaginaria y su traslación a la escritura alfonsina (primera manifestación de una tradición que tendría en Jorge Luis Borges y Roberto Bolaño a algunos de sus exponentes más insignes). Si bien Reyes trabajó esta línea en muchos textos, fue en uno en particular donde le otorgó sus propias características, que lo acercan más al ensayismo hispanoamericano.

Retratos reales e imaginarios se publicó en México en 1920, en la editorial Lectura Selecta; Reyes recopiló el material y se lo envió a Francisco González Guerrero por conducto de Genaro Estrada ${ }^{5}$. El volumen incluía un proemio donde el autor indicaba que había «publicado en la Prensa de Madrid unas notas, unos esbozos, reseñas, extractos de lecturas y comentarios, que yo quisiera haber escrito con sencillez». Luego exponía su metodología: «Escojo del montón estos quince artículos, y los envío — fiel— a los amigos de mi tierra...». El envío iba acompañado de un mensaje: «Conservaos unidos. Sacad razones de amistad de vuestras diferencias como de vuestras semejanzas» ${ }^{6}[$ Reyes, 1980: 403]. Pues la muerte asecha todo el tiempo y, al final, nos vencerá, parece sugerir la misiva. El proemio opera, aquí, como mecanismo argumentativo para demostrar la unidad de los textos ensayísticos que componen el libro, la mayoría de ellos provenía del diario madrileño El Sol, fundado

\footnotetext{
${ }^{5}$ En su Historia documental de mis libros, un proyecto bio-bibliográfico que Reyes comenzó a redactar al mediar la década del cincuenta, explicó, de nueva cuenta, que el libro había surgido «... de mis colaboraciones en El Sol de Madrid, y se lo envié a Francisco González Guerrero, director de la colección, también por conducto de Genaro Estrada, a fines de 1919» [1990: 262].

${ }^{6}$ En la primera edición de Retratos reales e imaginarios (México: Lectura Selecta, 1920), el índice, con el orden original de los quince textos, era el siguiente: 1) «Madama Lucrecia, último amor de don Alfonso el Magnánimo», 2) «Dos centenarios (el cardenal Cisneros, Lutero)», 3) «Antonio de Nebrija», 4) «Chateaubriand en América», 5) «Américo Vespucio», 6) «Fray Servando Teresa de Mier», 7) «Fortunas de Apolonio de Tiro», 8) «Don Rodrigo Calderón»,9) «Gracián y la guerra», 10) «Felipe IV y los deportes», 11) «Napoleón I, orador y periodista», 12) «Un abate francés del siglo XVIII», 13) «El obispo de Orense», 14) «En la casa de Garcilaso» y 15) «Francisco Codera y Zaidín». Para los fines de este ensayo, utilizaré tanto esta edición como la de las Obras completas.
} 
el 1 de diciembre de 1917 por Nicolás María de Urgoiti, y bajo la «dirección intelectual» de José Ortega y Gasset:

\footnotetext{
Se fundó El Sol —recordaría Reyes en Historia documental de mis libros-, diario en que José Ortega y Gasset hacía de Eminencia Gris, Manuel Aznar era el secretario de Consejo de Administración, y que dirigía Félix Lorenzo, ex director de El Imparcial, y donde se me confió la página de los jueves dedicada a «Historia y Geografía». Había ciertos días de la semana para la biología y la medicina, la economía política, la educación, etcétera [1990: 193].
}

Los ensayos recopilados adquieren, en su conjunto, cierta unidad formal. El título asocia la escritura con una técnica pictórica. El retrato no es solo visual, sino existencial: la descripción revela la figura, pero también rasgos particulares de la personalidad, aderezados con algunos elementos ficcionales e imaginativos. El retrato, con la invención de la fotografía, aumenta la percepción del instante fijado en la placa, algo hay ahí de ecfrástico, de descriptivo, pero sobre todo de revelación: ve más allá de la imagen retratada.

El primero de los textos, sobre Madama Lucrecia, el ensayista rescata y reinventa la historia de un personaje desconocido, al que solían confundir con la otra Lucrecia, la esposa de Colatino, víctima de la violación de Sexto Tarquino, y detonante, según la leyenda, de la caída de la monarquía romana. El viraje, de la Lucrecia romana a la Lucrecia renacentista, nos muestra la intención de evitar la biografía y elaborar una vida (una vida con base en la imaginación, sí, pero también en la documentación y en la interpretación crítica de dichos documentos); una vida que parte de las confusiones, el azar y la reelaboración literaria: en 1909, las demoliciones llevadas a cabo en torno al monumento de Víctor Manuel, en Roma, hacen resurgir el callejón de Madama Lucrecia (que había vivido ahí en la primera mitad del siglo XV: hija de Nicola d'Alagno y último amor de Alfonso I, rey de Aragón). Casi un siglo antes, en 1826, hasta ahí había llegado, motivado por la leyenda del personaje, Prosper Mérimée. La concatenación de encuentros y desencuentros se alarga hasta llegar al ensayo de Reyes. Su vida, concentrada en unas cuantas acciones, casi todas ellas de índole privada, deja un tenue rastro que el ensayista rescata y recrea: «Lucrecia es el hada buena del nuevo hogar. Castigada por el destino, cree haber descubierto, entre sus nostalgias, que la verdadera felicidad es siempre algo humilde, y que más consiste en darse a los otros que en preocuparse gran cosa de uno mismo» [1980: 411]. ¿Cómo aborda Reyes el género de la biografía? Siguiendo, en parte, a Marcel 
Schwob, el regiomontano hace del biógrafo a un literato, el cual está obligado a escribir una obra única y singular. El ensayista no es un historiador: la verdad resulta, entonces, un aspecto secundario y menos relevante. Lo fundamental son los detalles elegidos para resaltar las particularidades de una vida, con respecto a su entorno y su circunstancia.

Uno de los pocos críticos que han abordado el tema de las vidas imaginarias de manera extensa es Cristian Crusat. En su ensayo Vidas de vidas. Una historia no académica de la biografía. Entre Marcel Schwob y la tradición hispanoamericana del siglo XX, propone una "contrahistoria» (esa visión no académica) de la literatura que dé cuenta de cómo los autores dialogan (vía la escritura y la lectura) con otros autores del pasado, lo cual pone en jaque a los recursos racionales de la tradicional historiografía literaria, que persigue un orden cronológico y sucesivo. Es una perspectiva inversa a los manuales: es la obra misma la que contiene los datos y las fuentes.

Tal modalidad narrativa opera desde el nivel sincrónico de la tradición: recrea, vía la ficción, las particularidades de las personas y no los rasgos que los han hecho destacar históricamente. Surge en un momento específico: en ciertas crisis de la modernidad que hacen sentir su condición liminal. Algo particular de los campos literarios modernos: «Se trata, en lo esencial, de un espacio autónomo, cuya economía se basa en una lógica específica que depende de los valores atribuidos a una u otra obra, y según el género literario al que pertenezca» [2015: 64].

El aproximamiento sincrónico procede, como sabemos, del enfoque lingüístico de Ferdinand de Saussure. Crusat hace visible el vínculo entre los trabajos del lingüista suizo y los ensayos fundacionales de Marcel Schwob, en particular los reunidos en sus Vidas imaginarias, publicados en 1896. «El arte — dice ahí Schwob— es lo contrario de las ideas generales, describe solo lo individual, no desea sino lo único. No clasifica, desclasifica» [1986: 11]. Schowb hace visible una genealogía de biógrafos heterodoxos que se remonta a Diógenes Laercio y Plutarco en la antigüedad, y a John Aubrey, James Boswell y Thomas de Quincey, en la era moderna. Es innegable el vínculo de este modelo narrativo con el auge y la hegemonía de las biografías en la modernidad ${ }^{7}$ como vía de legitimación de la figura de autor y del concepto específico de literatura. En palabras del célebre biógrafo James Boswell, cuando, al emprender su monumental Vida de Samuel Johnson, declaraba su «intención de escribir, no su panegírico, que habría de ser un cúmulo de elogios, sino su vida,

\footnotetext{
${ }^{7}$ Crusat señala: «Entre otros mecanismos, cabe reseñar la función legitimadora de la biografía, cuya emergencia en el siglo XVIII respondió al fundamental papel que esta desempeñaría en relación con el reconocimiento de la figura del escritor y de su aportación individual en la relativamente nueva categoría denominada "literatura"» [2015: 121-122].
} 
pues, por grande y bueno que haya sido no debe suponerse que fuera un dechado de perfección» [Boswell, 2007: 24].

El otro modelo narrativo en el cual se apoya Reyes es Walter Pater. Pater publicó en 1892 sus Imaginary Portraits. Vale aquí un breve apunte: en la biblioteca personal de Reyes se conserva la edición de 1905, publicada por The Macmillan Company, con los subrayados del escritor regiomontano. El libro de Pater presenta cuatro relatos (o retratos): «A Prince of Court Painter» (sobre el pintor JeanAntoine Watteau), «Denys L'Auxerrois», «Sebastian van Storck»y «Duke of Rosenmold». Quizá el más cercano al proyecto de Reyes sea el primer texto. Una lectura comparativa arrojaría, sin embargo, varios contrastes. Escrito como fragmentos de un diario francés, perteneciente a un testigo de la época: el hijo del maestro y dueño del taller de pintura donde Watteau comenzaba su carrera de artista en Valenciennes, al comenzar el siglo XVIII, el texto es la ficcionalización del aprendizaje estético del pintor y del desarrollo de su temática favorita, las fêtes galantes:

\footnotetext{
And just where the crowd was busiest young Antony was found, hoisted into one of those empty niches of the old Hôtel de Ville, sketching the scene to the life, but with a kind of grace - a marvellous tact of omission, as my father pointed out to us, in dealing with the vulgar reality seen from one's own window — which has made trite old Harlequin, Clown, and Columbine, seem like people in some fairyland; or like infinitely clever tragic actors, who, for the humour of the thing, have put on motley for once, and are able to throw a World of serious innuendo into their burlesque looks, with a sort of comedy which shall be but tragedy seen from the other side [1905 a: 1-2].
}

El contraste entre la escritura de Pater y la de Reyes es notable, a pesar de lo que señala Crusat en repetidas ocasiones a lo largo de su ensayo: «Los textos que integran los Retratos reales e imaginarios muestran una gran afinidad con el género ensayístico y, por ende, con la obra Walter Pater» [2015: 270]. Y, una página más adelante: «Confeso lector de Pater, Alfonso Reyes pudo encontrar en otra obra del ensayista inglés, Imaginary Portraits, un nuevo modelo para sus retratos reales e imaginarios» [2015: 271]. Como podemos apreciar de la cita, Pater recurre a la ficción de manera directa: reescribe el diario de un testigo de la vida, o mejor, de la formación artística de Watteau. Reyes experimenta con el ensayo, pero desde una postura más cercana al documento. Es verdad que la lectura de Pater fue importante en su desarrollo literario, pero sobre todo en su acercamiento 
a los clásicos. La influencia de otro libro del escritor inglés, Plato and Platonism fue fundamental', y en eso sí concuerdo con Crusat. En rigor, el ensayista mexicano se separa tanto de Schwob (en lo relativo al uso excesivo de la imaginación) y a Pater (en la novelización de los hechos). Para el discurso ensayístico alfonsino es más importante la interpretación crítica de ciertos momentos de la vida de los personajes retratados (que puede ser secundario tanto para los biógrafos tradicionales como para los cultivadores de la recreación de vidas). Si Schwob persigue la originalidad y Pater la formación estética, Reyes anda en busca de ciertas y discretas formas de disidencia de múltiples tradiciones.

\section{El discurso ensayístico en la escritura alfonsina}

Uno de los artilugios ensayísticos que Reyes pone en marcha en Retratos reales e imaginarios es la efeméride. La prensa moderna había hecho del almanaque un detonante para la reelaboración de temas. Reyes trata de darle la vuelta al tópico, resignificando el viejo deseo de Auguste Comte de elaborar un calendario positivista donde se celebrasen los logros de los bienhechores de la humanidad: «Nada se parece más a este sueño —-muy ridiculizado después por los que solo vieron en él lo que tiene de pedantería pueril_ que la actual costumbre, cada vez más establecida de conmemorar "centenarios"» [1980: 412].

La efeméride opera, en el discurso ensayístico alfonsino, como el pretexto para reescribir la historia cultural y literaria. A través de la vida como modelo narrativo se resaltan las particularidades en oposición a los rasgos centrales e históricos del personaje a recordar. En el caso de Retratos reales e imaginarios, Reyes compara y opone las vidas del cardenal Francisco Jiménez de Cisneros y la de Martín Lutero (muertos ambos en 1517, y cuyos respectivos centenarios se celebran en 1917), y con ello resalta la diversidad de dos tradiciones culturales y literarias contrarias: la de la reforma y la de la contrarreforma, de las cuales uno es iniciador y el otro antecedente.

El discurso ensayístico desplegado en estos textos se convierte en contrapunto de la tradicional manera de redactar biografías: se establece un diálogo entre el ensayista y sus biografiados, donde los rasgos descritos y resaltados hablan también de la personalidad del propio autor. El caso particular del texto dedicado a fray Servando Teresa de Mier es revelador en más de una manera, y mucho nos dice

\footnotetext{
${ }^{8}$ Pater establece la genialidad de Platón no en el tratamiento del tema, sino en el de la forma: una estrategia para apropiar de las tradiciones que sería sumamente útil para Reyes y su generación: «lt is hardly an exaggeration to say that in Plato, in spite of his wonderful savour of literary freshness, there is nothing absolutely new: or rather, as in many other very original products of human genius, the seemingly new is old also, a palimpsest, a tapestry of which the actual threads have served before, or like the animal frame itself, every particle of which has already lived and died many times over. Nothing but the life-giving principle of cohesion is new; the new perspective, the resultant complexion, the expressiveness which familiar thoughts attain by novel juxtaposition. In other words, the form is new. But then, in the creation of philosophical literature, as in all other products of art, form, in the full signification of that word, is everything, and the mere matter is nothing» [Pater, 1905 b: 3-4].
} 
de esa forma original de recrear vidas. Mier, al igual que Reyes, era oriundo de Monterrey y, como él, se enfrentó a la historia nacional de su país y vivió el destierro de manera personal. Perseguido desde 1794 por escribir un sermón heterodoxo, donde afirmaba la presencia de Santo Tomás en la era prehispánica (y de refilón cuestionaba el discurso evangelizador de la Conquista), el padre Mier peregrino por Europa, escapando de cárceles y volviéndose insurgente luchó por la independencia de México, además de escribir, al final de su vida, unas increíbles y singulares Memorias.

Reyes elige la figura de su paisano, el fraile dominico, como estrategia de legitimación y hace de la escritura heterodoxa de este el antecedente de su propio registro literario (regiomontano como él; exiliado, como él; buscando la legitimación intelectual, como él). «El venir de tierras tan distantes le daba un prestigio casi mitológico. Y todo eso lo sabía él aprovechar admirablemente» [1980: 442]. Este ensayo, en rigor, fue consecuencia del prólogo que Reyes escribió para la edición madrileña de las Memorias de Mier, publicadas por la Editorial-América, en su colección Ayacucho, a cargo del escritor venezolano Rufino Blanco Fombona. Tanto el ensayo como la edición le sirvieron a Reyes como estratagema de reconocimiento. Reyes convirtió a Mier en su ancestro literario: una manera de mostrar sus credenciales en el campo literario español. A las disparatadas Memorias, les confirió la singularidad de una vida envuelta en circunstancias peculiares. (El ensayo, además, se conecta directamente con otro de los textos del libro: «Chateaubriand en América», pues en sus Memorias fray Servando confesó haber traducido en París, en 1804, la novela Atalá del francés, convirtiéndose así en el introductor del romanticismo en la lengua española. Blanco Fombona obligó a Reyes a consignar en el prólogo que el autor de dicha traducción fue el venezolano Simón Rodríguez, a la sazón compañero de aventuras parisinas de Servando. Vale decir que en ese momento tal versión castellana de Atalá estaba perdida, por lo que la disputa tenía mucha vigencia. Años después el descubrimiento de la novela confirmó las sospechas de Blanco Fombona: Rodríguez fue el traductor original. Reyes nunca estuvo de acuerdo y aquí configura una estrategia argumentativa para refutarlo).

Otras de las vidas que trabaja en el libro son las de Antonio Nebrija, Américo Vespucio, Rodrigo Calderón, y del erudito arabista Francisco Codera y Zaidín. Cada uno de estos personajes representa, en mayor o menor medida, una forma de variación o heterodoxia. De Nebrija, por ejemplo, no rescata el perfil oficialista de gramático del imperio, sino el de un rebelde que, al «buscar la ley en el nuevo fenómeno», termina por «demostrar que esta lengua popular de España también era susceptible de reglas», y con ese gesto le devolvía «su dignidad latina», para así «restaurar a la hija 
española en el trono de la familia romana» [1920: 46]. ¿No era, acaso, la misma estrategia que Reyes deseaba aplicar, mutatis mutandis, con respecto a la relación entre las literaturas hispanoamericanas y la española? Rescatar la valoración de las formas particulares del habla (de nuevo: el nivel sintagmático de una lengua y una literatura), para reconocer la riqueza del conjunto.

Sobre Américo Vespucio, Reyes realiza un contraste entre la fama de Colón y la nebulosa que envuelve la figura del navegante italiano: «¿Y qué se dice del florentino Vespucio? Que sus viajes fueron imaginarios; que quiso robar la hija a Colón; que — ambicioso— logró dar su nombre a lo que de ninguna manera le pertenecía; y, finalmente, que América se debería llamar Colombia» [1920: 71]. Las conjeturas, las leyendas, los mitos: todo lo que rodea la vida de Vespucio le interesa a Reyes: ve en esos discursos semificcionales el imaginario que se proyectaría sobre el otrora llamado «nuevo mundo». El tema americano cumple en los ensayos de Reyes el papel de detonante para la relectura de las relaciones entre Occidente y las nuevas naciones hispanoamericanas (un asunto que trabajará con mayor intensidad en sus ensayos de la década del treinta, como «Notas para la inteligencia americana»).

De Rodrigo Calderón, conde de la Oliva de Plasencia y marqués de Siete Iglesias, se configura un retrato centrado en su estoicidad ante la tortura y la muerte. ¿Cómo se puede transitar del poder al calabozo? ¿De los privilegios a la tortura? Para el ensayista, las peripecias de la vida de este personaje encierran los engranajes de la sociedad monárquica: «Don Rodrigo Calderón, sin ser nada, lo era todo en el reino: era el favorito. Si era amable, no lo sabemos. Acaso, como dice Quevedo que se sospechaba, era más bien cómplice, y como tal, poderoso mientras indispensable» [1920: 129].

También se ocupa de personaje literarios, como el Anacarsis del Viaje de Anacarsis El Joven por la Grecia, a mediados del siglo IV de la era vulgar (1788) de Jean-Jacques Barthélemy. En el ensayo «Un abate del siglo XVIII» establece sus marcas referenciales, destacando la elaboración de su propio mapa literario: «Hay dos Anacarsis célebres en la historia de las letras. El primero es aquel filósofo escita cuyas aventuras de paleto intelectual en la antigua Atenas nos cuenta Diógenes Laercio y que se sorprendía mucho de ver cómo los griegos, teniendo leyes contra los injuriadores, honraban a los atletas que se hieren y matan [...]. El segundo —acaso más célebre y seguramente inspirado en el primero- es aquel cuyos viajes alimentaron la infancia del desventurado "CharBovari" de Flaubert» [1980: 477]. 
En su ejercicio crítico y diferenciador, expone Crusat: «Garcilaso de la Vega, Chateaubriand y Baltasar Gracián son los tres únicos escritores, en sentido estricto, retratados en Retratos reales e imaginarios» [2015: 279]. Y a continuación establece las pocas semejanzas con las Vidas imaginarias: Reyes se queda en el documento. Sin embargo, no realiza una biografía en el sentido lato, sino un ensayo crítico. La escritura de Gracián, por ejemplo, le sirve para reflexionar en torno a la literatura de guerra, inaugurada, en sus palabras, por Sthendal, para, inmediatamente, anteponer la excepción, Gracián: «Y Gracián, que siempre había creído en el contagio de las cualidades heroicas y aún había escrito libros jactándose de saber formar héroes [...], tuvo ocasión de asistir a la victoria de Lérida y - a creer de su propio testimonio- de comunicar a los combatientes algo de valor sobrenatural» [1920: 140].

Sin negar, como ya he sugerido, el vínculo de los Retratos reales e imaginarios con los respectivos modelos narrativos de Schwob y Pater, yo colocaría este libro como una de las piedras fundacionales del discurso ensayístico hispanoamericano, en tanto sus estrategias críticas para leer diversas tradiciones literarias y cultuales. En ese sentido, las páginas dedicadas a fray Servando Teresa de Mier, o a Américo Vespucio, juegan un rol legitimador de la propia condición de Reyes como escritor venido del «nuevo mundo».

\section{Los Retratos reales e imaginarios y el discurso ensayístico hispanoamericano}

¿Cómo fue la recepción primigenia de este libro? A diferencia de lo que pasaría con los primeros ejercicios ensayísticos de Borges, a Reyes se le tomó muy en serio, demasiado. Los ensayos se leyeron como biografías convencionales. $\mathrm{O}$, en caso contrario, no se captó la carga imaginativa e irónica que los alimentaba. Al evocar la aparición del texto en su Historia documental de mis libros, en 1955, Reyes señalaba cómo "José María Chacón me dijo con sorna: "Supongo que ese elogio final a Codera y Zaidín es un verdadero retrato imaginario, porque el pobre señor era un escritor pesadísimo". Es posible: yo no me refería al escritor ni a su estilo, sino a la agilidad mental y al ingenio casi fabril del viejo arabista» [1990: 262].

Por otra parte, intelectuales como el peruano Francisco García Calderón le advertía a Reyes el peligro de ser «extremadamente objetivo» en el ensayo sobre Cisneros y Lutero. Ni uno ni otro encontraron el punto medio. No leyeron los textos como ensayos sino como notas periodísticas. 
En el ámbito literario mexicano, fue recibido tibiamente, por decir lo menos. Los amigos a quienes dedicaba el libro Reyes estaban, o bien en el exilio, o bien luchando por imponer nuevas instituciones culturales y educativas. En 1920, el gobierno de Venustiano Carranza era derrocado por Álvaro Obregón (Carranza moriría asesinado en mayo de ese año), comenzando así la primera gran etapa de la «institucionalización revolucionaria». En ese proceso, la literatura viviría un periodo de definiciones y orientaciones marcadas. El problema de la representación de lo nacional ocuparía largas polémicas. En el marco de esos debates, la literatura de Reyes parece ubicarse en una posición excéntrica, con sus propias preocupaciones y obsesiones. La historia familiar estaba para él marcada por la historia nacional. La condición mexicana resultaba un conflicto vivo, hiriente. Esto no quiere decir, sin embargo, que su escritura fuera evasiva, al contrario: representaba un diálogo directo con su presente.

Retratos reales e imaginarios tardaría más de treinta años en reeditarse. La segunda edición formaría parte del tomo III de las Obras completas (lanzado al público en 1955). Publicado dentro del proyecto de las Obras completas, el libro ocuparía inmediatamente un lugar complementario dentro del corpus de la producción literaria alfonsina escrita en España. Pero sería inmediatamente catalogado como parte de un proceso formativo, documento relativo a la historia y no a la literatura.

¿Qué hay detrás de la redacción de Retratos reales e imaginarios? Primero: la visibilidad del vínculo entre ciertas tradiciones heterodoxas de la modernidad literaria finisecular. Hay un poco más de veinte años de diferencia entre la publicación de Vidas imaginarias y la aparición del libro de Reyes. En este lapso temporal el desarrollo y la profesionalización de la prensa en el orbe hispánico fue fundamental: como se mencionó en el proemio, todos los ensayos aparecieron primero en los periódicos madrileños. Segundo: ¿cuál es la relación de este género literario con el canon? La desestabilidad de los modelos hegemónicos a través de una sutil crítica al sistema de valores imperantes. Lo que estoy intentando decir es que Alfonso Reyes utilizó el ensayo (este tipo peculiar de ensayo) para introducir nuevas formas de expresión y crear a su vez nuevos cuadros de lectores. Desde la prensa madrileña, el autor mexicano coloca temas y promueve diversas modales narrativas vinculadas con la exploración del ensayo.

El impacto no es visible sino hasta muchos años después, pues opera más desde la conducta heterodoxa del culto compartido por unos cuantos iniciados. La parte más creativa del ensayo alfonsino (donde Retratos reales e imaginarios cumple un rol protagónico) coincide con el auge de 
las vanguardias poéticas latinoamericanas; pero de estas solo toma ciertos impulsos y perspectivas. Reyes establece una nueva forma de conducta en el campo literario: la del escritor que no solo aspira a vivir de su pluma, sino que hace de la escritura su ética, una forma de política. En este aspecto, el escritor mexicano coloca el ensayo en un espacio intermedio, justo en el cruce de la autonomía estética y el pensamiento ético y comprometido. Le interesa la indagación por la identidad, pero solo como forma de reconocimiento supranacional (y no tanto como invención política o imposición del estado-nación).

No es de extrañar que, mientas el ensayo latinoamericano entra, a partir de la década del veinte, en un momento de revisión crítica de lo nacional (ahí están como prueba los escritos de Mariátegui, de Martínez Estrada y de Samuel Ramos, entre otros), Reyes explora la condición continental: sus ensayos trabajan la relación de América Latina con Occidente, pero no como una extensión más (al estilo de Rodó), sino como complemento que aporta su dosis de originalidad y su propia constitución heterogénea. Los contrastes entre la misma región (el norte y el sur de la América Latina), la visión continental, la relación de la cultura con la pedagogía, el civismo y la política, todos estos temas conforman el ensayismo de Reyes de esta época. Y ahí están sus lecturas, ya referidas, sobre la figura de fray Servando Teresa Mier.

Con Reyes, el género alcanza una madurez inusual en su contexto. La región experimenta, en general, procesos de modernización de corte popular, donde se comienza a atender las demandas (largamente desatendidas) de justicia social y las exigencias de acceso a la educación masiva.

En la mayoría de estos textos existe optimismo respecto al futuro inmediato, pero también se hace patente la necesidad del conocimiento propio. Se busca colocar a la tradición intelectual latinoamericana en la posición de interlocutor.

Reyes abrió el camino por el cual transitaría, con mayor éxito, Jorge Luis Borges, pues si bien este reconoció tardíamente la influencia de las Vidas imaginarias (en el prólogo a una edición española del libro de Schwob confesó: «Hacia 1935 escribí un libro candoroso que se llamaba Historia universal de la infamia. Una de sus muchas fuentes, no señalada aún por la crítica, fue este libro de Schwob» [Borges, 1986: 9]), nunca dejó de reconocer su deuda para con Reyes, una deuda que, más que en el estilo, se basaba en la manera en que se leía y configuraba una tradición. El mismo Roberto Bolaño se encargó de reforzar y hacer visible este vínculo, cuando señaló que Borges «se puso a escribir una historia en donde la épica solo es el reverso de la miseria, en donde la ironía, el humor 
y unos pocos y esforzados seres humanos a la deriva ocupan el lugar que antes ocupara la épica». Y finalmente apunta: «El libro [se refiere, por supuesto, a Historia universal de la infamia] es deudor de los Retratos reales e imaginarios que escribiera su amigo y maestro Alfonso Reyes, y a través del libro del mexicano, de las Vidas imaginarias, de Schwob, a quien ambos querían» [2004: 290-291].

Por su parte, Crusat establece, al estudiar la genealogía de Historia universal de la infamia: «No hay que olvidar que algunos de estos procedimientos proceden directamente del fructífero magisterio que Borges recibió de Alfonso Reyes, de quien sin embargo disentiría a la hora de armar su propio conjunto de biografías» [2015: 297]. La diferencia radicaría en el predominio, en el caso de la escritura borgeana, de la ficción sobre el ensayo, y la deformación de los rasgos biográficos.

No es casualidad tampoco que, a partir de los últimos años, Reyes «haya regresado» y su presencia esté nutriendo a las nuevas generaciones de ensayistas y críticos. ¿Qué han —hemosencontrado en él? Antes que nada, una conducta literaria; pero también a un lector atento que supo enriquecer el género otorgándole la posibilidad, la infinita posibilidad, de la ficción, del contraste, del juego de miradas. Y finalmente: hemos encontrado a un escritor que instaló a la figura del ensayista en el centro mismo de la vida cultural, un sujeto sin pretensiones de objetividad, pero con la voluntad de diálogo. No es poca cosa... 


\section{BIBLIOGRAFÍA}

BARRERA ENDERLE, Víctor: El centauro ante el espejo. (Charlas y apuntes sobre el ensayo). Monterrey: Universidad Autónoma de Nuevo León, 2017.

- «El reverso del tapiz: la escritura de Visión de Anáhuac», en Alfonso Reyes: Visión de Anáhuac. Visiones y revisitaciones. Una lectura crítica, edición de José Javier Villarreal. Monterrey: Facultad de Filosofía y Letras / UANL, 2016, pp. 145-156.

: Lectores insurgentes. La formación del discurso crítico hispanoamericano (1810-1870). La Habana: Casa de las Américas, 2013.

BOLAÑO, Roberto: Entre paréntesis. Barcelona: Anagrama, 2004.

BORGES, Jorge Luis: Prólogo a Marcel Schowb: Vidas imaginarias. Barcelona: Hyspamérica / Ediciones Orbis, 1986.

BOSWELL, James: Vida de Samuel Johnson, presentación de Frank Brady, edición y traducción de Miguel Martínez-Lage. Barcelona: Acantilado, 2007.

CRUSAT, Cristian: Vidas de vidas. Una historia no académica de la biografía. Entre Marcel Schwob y la tradición hispanoamericana del siglo XX. Madrid: Páginas de Espuma, 2015.

CONN, Robert T.: The Politics of Philology. Alfonso Reyes and the Invention of the Latin American Literary Tradition. Londres: Associated University Presses, 2002.

FOUCAULT, Michael: Las palabras y las cosas, traducción de Elsa Cecilia Frost. México: Siglo XXI, 1978.

MAÍZ, Claudio: El ensayo: entre género y discurso. Debate sobre el origen y funciones en Hispanoamérica. Mendoza, 2004.

PATER, Walter: Imaginary Portraits. Nueva York: The Macmillan Company, 1905. Plato and Platonism. Nueva York: The Macmillan Company, 1905.

REYES, Alfonso: Diario, I, 1911-1927, edición crítica de Alfonso Rangel Guerra. México: Fondo de Cultura Económica, 2010.

—. El plano oblicuo, El cazador, El suicida, Aquellos días, Retratos reales e imaginarios. Obras completas, vol. III. México: Fondo de Cultura Económica, 1980.

— — Oración del 9 de febrero, Historia documental de mis libros... Obras completas, vol. XXIV, edición de José Luis Martínez. México: Fondo de Cultura Económica, 1990.

—_: Retratos reales e imaginarios. México: Lectura Selecta, 1920. 
: Visión de Anáhuac, Las vísperas de España. Obras completas, vol. II. México: Fondo de Cultura Económica, 1995.

RODÓ, José Enrique: Ariel. Obras completas, edición, notas y estudio de Emir Rodríguez Monegal. Madrid: Aguilar, 1957.

SAID, Edward: «El islam, la filología y la cultura francesa», en El mundo, el texto y el crítico, traducción de Ricardo García Pérez. Barcelona: Debate, 2004.

SCHWOB, Marcel: Vidas imaginarias, traducción de Julio Pérez Millán y prólogo de Jorge Luis Borges. Barcelona: Hyspamérica / Ediciones Orbis, 1986. 